\title{
Changes in the profile of newly HIV-diagnosed men who have sex with men, Madrid, 2014 to 2019
}

Oskar Ayerdi Aguirrebengoa ${ }^{1,2}$, Mar Vera Garcia ${ }^{1}$, Teresa Puerta López ${ }^{1}$, Petunia Clavo Escribano ${ }^{1}$, Juan Ballesteros Martín ${ }^{1}$ , Clara Lejarrag Cañas ${ }^{1}$, Enrique Fuentes Ferrer ${ }^{3}$, Montserrat Raposo Utrilla ${ }^{1}$, Vicente Estrada Perez ${ }^{2,4}$, Jorge Del Romero Guerrero ${ }^{1}$, Carmen Rodríguez Martín ${ }^{1,2}$, Sandoval Study Group 1,2,3,4

1. Centro Sanitario Sandoval, Hospital Clínico San Carlos, IdISSC, Madrid, Spain

2. Universidad Complutense de Madrid, Madrid, Spain

3. Servicio de Medicina Preventiva, Insituto de investigación Sanitaria San Carlos, Universidad Alfonso X el Sabio, Madrid, Spain

4. Unidad de Infecciosas, Medicina Interna, Hospital San Carlos, IdISSC, Madrid, Spain

Correspondence: Oskar Ayerdi Aguirrebengoa (oskarayerdi@hotmail.com)

Investigators: The investigators are listed at the end of the article.

Citation style for this article:

Ayerdi Aguirrebengoa Oskar, Vera Garcia Mar, Puerta López Teresa, Clavo Escribano Petunia, Ballesteros Martín Juan, Lejarrag Cañas Clara, Fuentes Ferrer Enrique, Raposo Utrilla Montserrat, Estrada Perez Vicente, Del Romero Guerrero Jorge, Rodríguez Martín Carmen, Sandoval Study Group. Changes in the

profile of newly HIV-diagnosed men who have sex with men, Madrid, 2014 to 2019. Euro Surveill. 2021;26(47):pii=2001501. https://doi.org/10.2807/1560-7917.

ES.2021.26.47.2001501

Introduction: Knowing the factors associated with HIV transmission is necessary in order to design preventive programmes tailored to the epidemiological situation in each region and population. Aim: Our objective was to study the sociodemographic, clinical and behavioural characteristics of men who have sex with men (MSM) who were newly diagnosed with HIV infection. Methods: We carried out an observational, descriptive, study on all MSM newly diagnosed with HIV infection in one clinic for sexually transmitted infections (STI) and HIV clinic in Madrid between 2014 and 2019. Information on sociodemographic, clinical, and behavioural characteristics of participants per year of diagnosis was collected. Results: We detected a total of 1,398 people with HIV infection, 253 of whom were recent seroconverters ( $\mathrm{rSCV}$ ) with a median duration of documented seroconversion of 6 months. From the total, $97.9 \%$ infections were sexually transmitted and $\mathbf{2 . 1} \%$ involved injected drugs, i.e. slam practices. The average age was 32.9 years (range: 15.6-74.9), $51.8 \%$ were Spanish and $40 \%$ Latin American. These diagnoses decreased in Spanish people and increased in Latin Americans during the study period. Of the rSCV, $73.9 \%$ had condomless sex under the influence of drugs and $28.9 \%$ participated in chemsex sessions. Apps were used by $\mathbf{9 2 . 6 \%}$ rSCV for sexual encounters and $70.4 \%$ of them attributed HIV transmission to their use. Conclusions: Combination of HIV prevention strategies, as pre-exposure prophylaxis, should be reinforced among young MSM, especially those born in Latin America, those who use drugs for sex, and those who use apps in search of sexual contacts.

\section{Introduction}

Since the start of the AIDS epidemic, the interest in knowing the factors associated with the transmission of infection of the human immunodeficiency virus (HIV) has been constant in order to establish up-to-date prevention strategies aimed particularly at the most affected groups [1].

Numerous studies show that HIV transmission is higher in infected subjects who are unaware of their serostatus [2]. Thus, early diagnosis and highly active antiretroviral therapy (HAART) are essential tools for prevention. In 1987, the sale of the first drug, Zidovudine (AZT), was approved, but it was not until 1996 that the greater efficacy of combination ART changed the history of the infection [3,4]. Since then, advances in ART have dramatically improved the survival and quality of life of infected people [5]. Several studies have confirmed that seropositive patients with undetectable viral load under ART did not transmit the infection to their sexual partners $[6,7]$. Therefore, the reduction of the time between the transmission of HIV and the diagnosis and treatment of the infection is a priority in all prevention programmes for this disease. Several preventive measures have been used against HIV, such as the promotion of consistent condom use, sex education, screening for sexually transmitted infections (STI) and HIV, post-exposure prophylaxis (PEP) or early diagnosis and immediate ART, which is probably the measure that has had the greatest impact in recent years. In 2016, another preventive measure known as pre-exposure prophylaxis (PrEP) was approved in Europe, recommended by different health agencies and scientific societies such as the United States (US) Centers for Disease Control and Prevention (CDC), the World Health Organization (WHO), the European AIDS Clinical Society (EACS) or the Spanish AIDS Study Group (GeSIDA) [8-13]. In November 2019, the Ministry of Health announced the funding of PrEP in Spain as an additional measure of prevention against HIV within the National Health System [14]. According to UNAIDS 
TABLE 1

Study variables collected for men who have sex with men newly diagnosed with HIV, Madrid, 2014 to 2019

\begin{tabular}{|c|c|}
\hline Variables & \\
\hline Mode of transmission & Sexual; people who inject drugs \\
\hline Age & $\leq 19 ; 20-29 ; 30-39 ; 40-49 ; 50-59 ; \geq 60$ years \\
\hline Place of birth & Spain; Latin America; Other \\
\hline CD4+T-lymphocyte count & $\begin{array}{c}\text { Advanced disease }<200 \text { cells } / \mu \mathrm{L} ; \\
\text { late diagnosis } 200-350 \text { cells } / \mu \mathrm{L} ; 351-500 \text { cells } / \mu \mathrm{L} ; \\
\text { early diagnosis }>500 \text { cells } / \mu \mathrm{L}\end{array}$ \\
\hline Plasma HIV viral load & $\begin{array}{c}<37 \mathrm{cop} / \mathrm{mL} ; 37-1,000 \mathrm{cop} / \mathrm{mL} ; 1,001-10,000 \mathrm{cop} / \mathrm{mL} ; 10,001-50,000 \\
\operatorname{cop} / \mathrm{mL} ; 50,001-100,000 \mathrm{cop} / \mathrm{mL} ;>100,000 \mathrm{cop} / \mathrm{mL}\end{array}$ \\
\hline Prior negative results at the time of HIV diagnosis & Yes/no \\
\hline HIV recent seroconverters ${ }^{a}$ & Yes/no \\
\hline History of other $\mathrm{STI}$ & Yes/no \\
\hline Concomitant STI ${ }^{\mathrm{b}}$ at the time of HIV diagnosis & Yes/no \\
\hline Age of sexual debut & $\langle 15 ; 15-18 ; 19-25 ;\rangle 25$ years \\
\hline Number of sexual partners in the year before HIV diagnosis & $0-5 ; 6-25 ; 26-100 ;>100$ \\
\hline Number of sexual partners during lifetime & 1-10; 11-100; 101-1,000;>1,000 \\
\hline $\begin{array}{l}\text { Consistent condom use according to sexual activity in the year } \\
\text { before HIV diagnosis }\end{array}$ & Orogenital, vaginal or anal sex \\
\hline Sex worker & Yes/no \\
\hline Use of PEP and PrEP & Yes/no \\
\hline Use of drugs for sex in the year before the diagnosis of HIV & $\begin{array}{l}\text { Alcohol in 'in excess', cannabis, cocaine, poppers, ketamine, GHB, } \\
\text { ecstasy, mephedrone, methamphetamine; others }\end{array}$ \\
\hline Condomless sex under the influence of drugs & Yes/no and which \\
\hline Slam: parenteral drug use in the sexual context & Yes/no \\
\hline $\begin{array}{l}\text { Chemsex sessions: sexual relations with multiple people under the } \\
\text { influence of drugs }\end{array}$ & Yes/no \\
\hline $\begin{array}{l}\text { Use of apps to search for sexual contacts in the year before HIV } \\
\text { diagnosis }\end{array}$ & Yes/no \\
\hline
\end{tabular}

Cop: genome copies; GHB: gamma hydroxybutyrate; PEP: post-exposure prophylaxis; PrEP: pre-exposure prophylaxis; STI: sexually transmitted disease.

${ }^{a}$ HIV recent seroconverters were considered to be those who had a documented negative HIV serology in the 12 months before diagnosis or who were in the process of seroconversion.

b STI included Neisseria gonorrheae infection, Chlamydia trachomatis infection/lymphogranuloma venereum, syphilis, herpes simplex virus infection, anogenital condylomas, scabies, pediculosis pubis and hepatitis A, B and C.

We defined two categories of late presentation: late diagnosis with 350-500 cells/ $\mathrm{LL}$ CD4+ T-cell count; and advanced disease with less than 200 cells $/ \mu \mathrm{L}$.

data, there has been a $16 \%$ reduction in new HIV diagnoses globally, from 2.1 million in 2010 to 1.7 million in 2018 [15]. In some high-income countries, the implementation of preventive strategies in a combined manner and directed at target populations has been associated with an important decrease in new cases of HIV, even in men who have sex with men (MSM) for the first time in years [16-18].

In 2018, 26,164 new cases of HIV infection were reported in Europe, a rate of 5.6 per 100,000 people/ year [19]. According to the Sistema de Información sobre nuevos diagnósticos de VIH (SINIVIH) of the Ministry of Health, 3,244 new cases were detected in Spain in 2018, a rate of 8.65 per 100,000 inhabitants, the majority among MSM; the usual mode of transmission was sexual [20].
The objective of this work was to describe the sociodemographic, clinical and behavioural characteristics of MSM newly diagnosed with HIV infection between 2014 and 2019 in a reference centre for STI/HIV in Madrid and to analyse changes during that period.

\section{Methods}

We carried out an observational, descriptive study in a reference clinic for STI/HIV in Madrid between 2014 and 2019. That centre offers universal care without administrative barriers, attends to more than 30,000 consultations a year and is located in the heart of the city. All MSM with new HIV diagnosis during the 6-year period were invited by the health professional, on the same day or close to the diagnosis, to participate in the study; they were also offered linkage for immediate ART and STI screening. The treating physician compiled a complete clinical history of each patient based on the information on sociodemographic, clinical and 
New diagnoses of HIV infection among men who have sex with men $(n=1,398)$ and cases of recent seroconversion $(n=253)$ documented at one reference centre, Madrid, 2014-2019

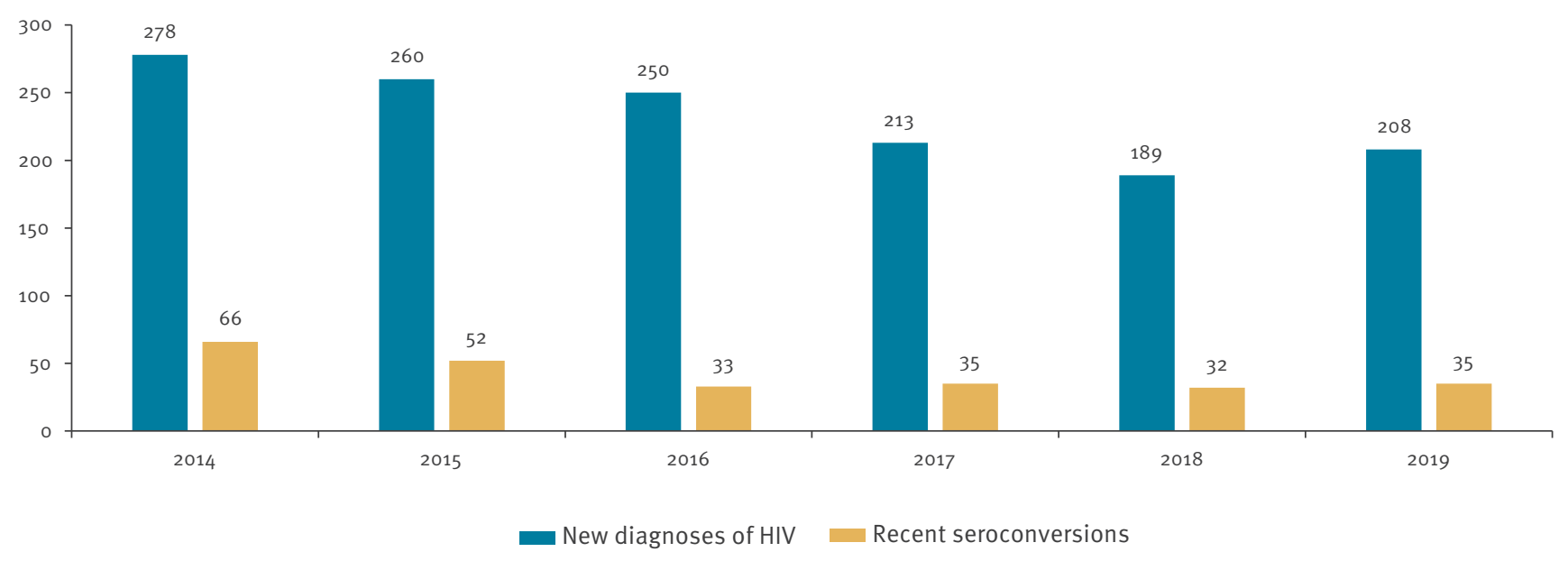

behavioural characteristics collected STI/HIV clinic. The collected variables are described in Table 1.

\section{Diagnostic techniques}

The detection of antibodies against HIV in serum was performed by fourth-generation chemiluminescence magnetic microparticle immunoassay (CMIA) (HIV $1 / 2 \mathrm{Ag}$ Ab Architect Abbott Laboratories, Wiesbaden, Germany) which detects antibodies to HIV-1/HIV-2 and p24 antigen of HIV-1. A positive result was confirmed by Western blot (BIO-RAD, Marnes-la-Coquette, France) and Geenius HIV $1 / 2$ Confirmatory Assay (BIO-RAD) techniques. The quantification of HIV plasma viral load was carried out through real-time PCR (Versant kPCR Siemens, Erlangen, Germany). After diagnosis, the $\mathrm{CD}_{4}{ }^{+}$T-lymphocyte count was determined using $\mathrm{CD} 45 /$ $\mathrm{CD}_{3} / \mathrm{CD} 8 / \mathrm{CD} 4$ flow cytometry (Epics $\mathrm{XL}$ and Aquios C.L. Beckman Coulter, Brea, US).

\section{Statistical analysis}

The qualitative variables are presented as absolute and relative frequencies. The quantitative variables are expressed as the mean and standard deviation (SD). No data imputation has been made, all denominators for calculations were based on available information. Unlike for the other variables, information on chemsex and apps were only collected from 2016 to 2019. Comparison of the trend of the qualitative variables of the new HIV diagnoses based on years was carried out with the chi-squared test for linear trend and the quantitative variables by the analysis of variance (ANOVA). The chi-squared for trend calculated was based on the Mantel-Haenzzel $(\mathrm{MH})$ statistic. This test, being based on a linear function of frequencies, is less demanding than Pearson's chi-square test. It can be applied with expected frequencies greater than 2. In all comparisons, the application conditions were met, except for the age variable. In that case, the ranges 50-59 and $\geq 60$ have been unified. For all tests, we accepted a significance value of $5 \%$. The statistical analysis of the data was carried out using the STATA 15.0 statistical package (StataCorp LLC, College Station, US).

\section{Ethical statement}

All data derived from medical histories were fully anonymised before access. The study protocol was approved by the IRB of Hospital Clínico San Carlos, approval number 20/795-E. The ethics committee waived the need for informed consent because the information obtained for the study was collected in routine clinical practice.

\section{Results}

Between 2014 and 2019, 1,398 new infections of HIV were diagnosed among MSM. For 253 of them, a recent seroconversion could be documented. During that period, we observed a downward trend in the number of cases and of recent seroconverters ( $\mathrm{rSCV})(p=0.034)$ (Figure 1).

Sociodemographic and clinical characteristics of men who have sex with men and who had newly diagnosed HIV infection

The most relevant characteristics of MSM with new HIV diagnoses are described by year in Table 2, from 2014 to 2019. Most transmissions (97.9\%) were sexual and $2.1 \%$ occurred in people who inject drugs (PWID). Intravenous drugs were used in a sexual context by all $2.1 \%$. This practice, known as slam, remains infrequent but has increased during the study period. The average age was 32.9 years $( \pm 8.8)$, ranging from 15.6 to 74.9 years. Diagnoses decreased among people born in Spain and increased among those born in Latin America, with a statistically significant trend ( $p$ linear trend (0.001). Diagnosis of HIV occurred at a younger age among Latin American compared with Spanish MSM, with a significant trend ( $p$ linear trend $<0.001$ ) (Figure 2). The majority were early diagnoses but, starting in 2016, the number of late diagnoses and 


\section{TABLE 2}

Most relevant sociodemographic and clinical characteristics of newly HIV-diagnosed men who have sex with men, 2014$2019(\mathrm{n}=1,398)$

\begin{tabular}{|c|c|c|c|c|c|c|c|c|c|c|c|c|c|c|c|}
\hline \multirow[t]{2}{*}{ Characteristics } & \multicolumn{2}{|c|}{$\begin{array}{c}2014 \\
n=278\end{array}$} & \multicolumn{2}{|c|}{$\begin{array}{c}2015 \\
n=260\end{array}$} & \multicolumn{2}{|c|}{$\begin{array}{c}2016 \\
n=250\end{array}$} & \multicolumn{2}{|c|}{$\begin{array}{c}2017 \\
n=213\end{array}$} & \multicolumn{2}{|c|}{$\begin{array}{c}2018 \\
n=189\end{array}$} & \multicolumn{2}{|c|}{$\begin{array}{c}2019 \\
n=208\end{array}$} & \multicolumn{2}{|c|}{$\begin{array}{c}\text { Total } \\
n=1,398\end{array}$} & \multirow[t]{2}{*}{$\begin{array}{l}p(\text { linear } \\
\text { trend })\end{array}$} \\
\hline & $\%$ & $n$ & $\%$ & $n$ & $\%$ & $n$ & $\%$ & $n$ & $\%$ & $n$ & $\%$ & $n$ & $\%$ & $n$ & \\
\hline \multicolumn{16}{|c|}{ Mode of transmission } \\
\hline Sexual & 99.6 & 277 & 99.2 & 258 & 98.8 & 247 & 96.2 & 205 & 96.8 & 183 & 95.7 & 199 & 97.9 & 1,369 & \multirow{2}{*}{$<0.001$} \\
\hline PWID/slam & 0.4 & 1 & 0.8 & 2 & 1.2 & 3 & 3.8 & 8 & 3.2 & 6 & 4.3 & 9 & 2.1 & 29 & \\
\hline \multicolumn{16}{|l|}{ Age (years) } \\
\hline$\leq 19$ & 1.4 & 4 & 0.4 & 1 & 1.2 & 3 & 1.9 & 4 & 1.6 & 3 & 0 & 0 & 1.1 & 15 & \multirow{5}{*}{0.151} \\
\hline $20-29$ & 40.6 & 113 & 44.2 & 115 & 41.2 & 103 & 43.7 & 93 & 49.7 & 94 & 47.6 & 99 & 44.1 & 617 & \\
\hline $30-39$ & 38.5 & 107 & 35.8 & 93 & 33.6 & 84 & 39.9 & 85 & 29.6 & 56 & 37.0 & 77 & 35.9 & 502 & \\
\hline $40-49$ & 15.5 & 43 & 15.0 & 39 & 19.2 & 48 & 10.8 & 23 & 12.7 & 24 & 10.6 & 22 & 14.2 & 199 & \\
\hline$\geq 50$ & 4.0 & 11 & 4.6 & 12 & 4.8 & 12 & 3.8 & 8 & 6.3 & 12 & 4.8 & 10 & 4.6 & 65 & \\
\hline \multicolumn{16}{|l|}{ Place of birth } \\
\hline Spain & 68.0 & 189 & 57.7 & 150 & $54 \cdot 4$ & 136 & 47.9 & 102 & 40.2 & 76 & 36.1 & 75 & 51.8 & 724 & \multirow{3}{*}{$<0.001$} \\
\hline Latin America & 25.2 & 70 & 31.9 & 83 & 36.0 & 90 & 42.3 & 90 & 55.0 & 104 & 58.7 & 122 & 40.0 & 559 & \\
\hline Other & 8.3 & 23 & 10.4 & 27 & 9.6 & 24 & 9.9 & 21 & 4.8 & 9 & 5.3 & 11 & 8.2 & 115 & \\
\hline \multicolumn{16}{|l|}{$\mathrm{CD}_{4}{ }^{+} \mathrm{T}$-cell count } \\
\hline$\leq 200$ & 6.2 & 15 & 6.0 & 13 & 5.4 & 11 & 11.9 & 23 & 11.6 & 19 & 9.2 & 17 & 8.1 & 98 & \multirow{5}{*}{$<0.001$} \\
\hline $201-350$ & 12.0 & 29 & 15.6 & 34 & 12.8 & 26 & 21.2 & 41 & 22.6 & 37 & 27.6 & 51 & 18.1 & 218 & \\
\hline $351-500$ & 16.2 & 39 & 22.5 & 49 & 23.6 & 48 & 25.9 & 50 & 31.7 & 52 & 25.4 & 47 & 23.7 & 285 & \\
\hline$>500$ & 65.6 & 158 & 56.0 & 122 & 58.1 & 118 & 40.9 & 79 & 34.1 & 56 & 37.8 & 70 & 50.1 & 603 & \\
\hline Unknown & NA & 37 & NA & 42 & NA & 47 & NA & 20 & NA & 25 & NA & 23 & NA & 194 & \\
\hline \multicolumn{16}{|l|}{ HIV viral load } \\
\hline$<37$ & 0.4 & 1 & 1.8 & 4 & 2.0 & 4 & 3.1 & 6 & 1.8 & 3 & 3.2 & 6 & 2.0 & 24 & \multirow{7}{*}{0.829} \\
\hline $37-1,000$ & 2.9 & 7 & 7.3 & 16 & 4.9 & 10 & 6.2 & 12 & 6.1 & 10 & 5.9 & 11 & 5.5 & 66 & \\
\hline $1,001-10,000$ & 17.4 & 42 & 10.6 & 23 & 14.3 & 29 & 17.1 & 33 & 17.1 & 28 & 14.1 & 26 & 15.0 & 181 & \\
\hline $10,001-50,000$ & 29.0 & 70 & 32.1 & 70 & 30.5 & 62 & 32.1 & 62 & 22.6 & 37 & 22.7 & 42 & 28.5 & 343 & \\
\hline $50,001-100,000$ & 17.0 & 41 & 13.3 & 29 & 20.7 & 42 & 15.0 & 29 & 15.9 & 26 & 11.9 & 22 & 15.7 & 189 & \\
\hline$>100,000$ & 33.2 & 80 & 34.9 & 76 & 27.6 & 56 & 26.4 & 51 & 36.6 & 60 & 42.2 & 78 & 33.3 & 401 & \\
\hline Unknown & NA & 37 & NA & 42 & NA & 47 & NA & 20 & NA & 25 & NA & 23 & NA & 194 & \\
\hline \multicolumn{16}{|l|}{ STI } \\
\hline History of STI & 70.9 & 197 & 62.3 & 162 & 71.6 & 179 & 69.0 & 147 & 70.4 & 133 & 76.0 & 158 & 69.8 & 976 & 0.074 \\
\hline Concomitant STI & 48.9 & 136 & 53.1 & 138 & 60.8 & 152 & 56.8 & 121 & 63.5 & 120 & 68.3 & 142 & 57.9 & 809 & $<0.001$ \\
\hline
\end{tabular}

NA: not applicable; PWID: people who inject drugs; STI: sexually transmitted infections.

No data imputation has been made, all denominators for calculations were based on available information (excluding those with missing information).

advanced disease increased with a statistically significant upward trend.

\section{Behavioural characteristics of men who have} sex with men and who were newly diagnosed with HIV infection

The majority of newly diagnosed MSM began sexual relations at an age between 16 and 18 years, had more than 10 sexual partners in the year before diagnosis and more than 100 sexual partners in their lifetime. Consistent condom use was $0.4 \%(5 / 1,295)$ in oral sex, $13.6 \%(176 / 1,295)$ in insertive anal sex and $19.4 \%(251 / 1,295)$ in receptive anal sex. From the total, $69.8 \%$ had a history of STI and $57.9 \%$ had concomitant STI at the time of the HIV diagnosis. The request of pharmacological prevention was low, 3.8\% had used PPE on some occasion and $1.1 \%$ had used PrEP. Use of alcohol 'in excess' or recreational drugs were recorded in $83.4 \%$, and $64.5 \%$ had condomless sex under their effects. Chemsex sessions were noted in $21.4 \%$, and $2.1 \%$ practiced slam (Table 3). Prior negative HIV test results were seen in $86.6 \%$ and recent seroconversion could be documented in $18.1 \%$. The $81.1 \%(697 / 860)$ use apps for sex.

Sociodemographic, clinical and behavioural characteristics among men who have sex with men and with recent $\mathrm{HIV}$ seroconversion Among the $253 \mathrm{HIV} \mathrm{rSCV}, 80.2 \%(n=203)$ were between 20 and 39 years-old; $65.6 \%(n=166)$ were of Spanish 


\section{FIGURE 2}

Average age at the time of HIV diagnosis, by place of origin (Spain or Latin America) among men who have sex with men, Madrid, 2014-2019 $(\mathrm{n}=1,398)$

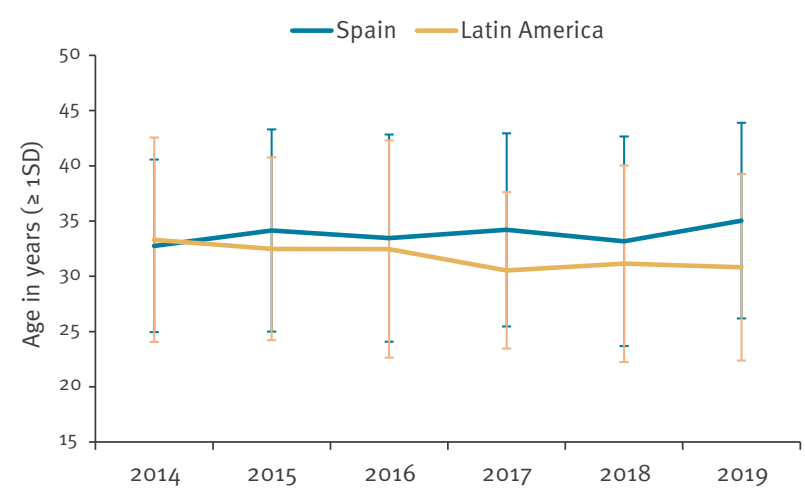

SD: standard deviation.

and $26.5 \%(n=67)$ of Latin American origin. Alcohol 'in excess' or recreational drugs were consumed on a regular basis by $88.1 \%(n=223)$, and $73.9 \%(n=187)$ had condomless sexual relations under their effects. The substances that were most associated with sex and having sexual relations without a condom were: mephedrone $(n=41 ; 100 \%)$, gamma hydroxybutyrate (GHB) $(n=59 ; 95.2 \%)$, methamphetamine $(n=17 ; 94.4 \%)$, ketamine $(n=28 ; 93.3 \%)$ and poppers $(n=107 ; 89.2 \%)$ (Figure 3). Use of some of these substances increased during the study period, particularly methamphetamine (Figure 4). Of the rSCV, 65 (28.9\%) participated in chemsex sessions with an upward trend, eight (24.2\%) in 2016,10 (28.6\%) in 2017, eight (25.0\%) in 2018 and $13(37.8 \%)$ in 2019 . Apps were used to search for sexual contacts by 207 (92.6\%) of the rSCV, with a stable trend during the period studied. The most common were: Grindr ( $n=171 ; 83.0 \%)$, Scruff $(n=61 ; 29.6 \%)$ and Wapo $(n=48 ; 23.0 \%)$. Transmission of the infection was attributed to a sexual contact found through apps by $157(70.4 \%)$.

\section{Discussion}

In our study, the percentage of people born in Latin America was higher and presented an upward trend, $25.2 \%$ in 2014 and $58.7 \%$ in 2019. In addition, the new HIV diagnoses among MSM born in Spain decreased significantly in our study, from $66.5 \%$ in 2014 to $36.1 \%$ in 2019, a more pronounced change than seen in the national figures [20]. In Spain, the number of new HIV diagnoses remains high among MSM, with a slower decline than in surrounding countries $[15,19]$. One of the reasons is the large number of cases originating from other countries with a high incidence of HIV infection, particularly from Latin America. According to the SINIVIH registry, $63.9 \%$ of all newly diagnosed people in 2019 were born in Spain and 22.9\% Latin America [20]. Our data match with those recorded in San Francisco where, from 2012 to 2018, the percentage of new HIV cases decreased significantly among white people and increased among African and Latino Americans [17]. The group with most new HIV cases in San Francisco changed from white to Latino between 2017 and 2018, while we saw a similar change in our work between 2018 and 2019.

In high-income countries, a downward trend in new HIV diagnoses has been observed, especially since 2016, and for the first time in the history of the HIV epidemic, also among MSM. This trend has been even more noteworthy in cities where a combination of HIV prevention strategies have been implemented with the inclusion of PrEP $[17,18]$. According to data published by the United Kingdom's (UK) National Health Service, new HIV diagnoses went down by 34\% globally from 2015 to 2019 [21]: The reported decline among MSM was significative, from a peak of 3,214 in 2014 and 2,079 in 2018 to 1,700 diagnosed in 2019 (a 47\% and 18\% drop, respectively). The steepest declines were observed among MSM of white ethnicity (2,550 in 2014, 1,425 in 2018 and 1,107 in 2019) and MSM born in the UK $(1,869$ in 2014, 950 in 2018 and 715 in 2019) [21]. In our study, the new HIV infections decreased more slowly. Other parts of the world, for example in Latin American countries, have experienced an increase in the incidence of HIV, the number of new infections in that region increased by $7 \%$ between 2010 and 2018 [15].

In our study, $47.6 \%$ of MSM diagnosed in 2019 were between 20 and 29 years-old and $37.0 \%$ between 30 and 39 years, compared with the national SINIVIH data where $26.9 \%$ newly diagnosed people were between 20 and 29 and $32.3 \%$ between 30 and 39 years-old [20]. The majority of new HIV diagnoses in Europe occur in people between 20 and 39 years of age, with a downward trend in all age groups, except in those older than 50 years, where it remains stable [19]. According to our temporal analysis, increasingly younger people were diagnosed with HIV. This trend was linear and significant among Latin Americans, whereas among Spanish people it remained stable at around 33 years of age.

If we compare the $\mathrm{CD}_{4}{ }^{+} \mathrm{T}$-lymphocyte counts at the time of HIV diagnosis between the Spanish national registry against in our study among MSM they were, in 2019, 378 vs 533 cells $/ \mathrm{mL}$ on average. There were $20.5 \%$ vs $9.2 \%$ of diagnoses with $<200$ cells $/ \mathrm{mL}$ advanced disease and $20.8 \%$ vs $27.6 \%$ with $201-350$ cells $/ \mathrm{mL}$ late diagnosis [20]. This difference between the data from Madrid and the governmental data reflect an earlier diagnosis in our STI/HIV clinic, probably related to the follow-up of seronegative people with risky practices. However, in the years 2017 to 2019, the $\mathrm{CD}_{4}^{+}$T-cellcounts at the time of diagnosis have been lower. This may be explained by later diagnosis among foreigners and the numerous diagnoses of acute infection, coinciding with the decrease in $\mathrm{CD}_{4}^{+} \mathrm{T}$-cells.

The WHO points out that MSM are highly vulnerable to acquiring HIV infection [22]. In this work, MSM presented 
TABLE 3

Most relevant behavioural characteristics of newly HIV-diagnosed men who have sex with men, 2014-2019 ( $\mathrm{n}=1,398)$

\begin{tabular}{|c|c|c|c|c|c|c|c|c|c|c|c|c|c|c|c|}
\hline \multirow[t]{2}{*}{ Characteristics } & \multicolumn{2}{|c|}{$\begin{array}{c}2014 \\
n=278\end{array}$} & \multicolumn{2}{|c|}{$\begin{array}{l}2015 \\
n=260\end{array}$} & \multicolumn{2}{|c|}{$\begin{array}{c}2016 \\
n=250\end{array}$} & \multicolumn{2}{|c|}{$\begin{array}{c}2017 \\
n=213\end{array}$} & \multicolumn{2}{|c|}{$\begin{array}{c}2018 \\
n=189\end{array}$} & \multicolumn{2}{|c|}{$\begin{array}{c}2019 \\
n=208\end{array}$} & \multicolumn{2}{|c|}{$\begin{array}{c}\text { Total } \\
\mathrm{n}=1,398\end{array}$} & \multirow[t]{2}{*}{$\begin{array}{l}p \text { (linear } \\
\text { trend) }\end{array}$} \\
\hline & $\%$ & $n$ & $\%$ & $\mathrm{n}$ & $\%$ & $\mathrm{n}$ & $\%$ & $\mathrm{n}$ & $\%$ & $\mathrm{n}$ & $\%$ & $\mathrm{n}$ & $\%$ & $\mathrm{n}$ & \\
\hline \multicolumn{16}{|c|}{ Age at sexual debut (years) } \\
\hline$<13$ & 5.4 & 15 & 5.8 & 15 & 3.2 & 8 & 3.8 & 8 & 4.2 & 8 & 7.7 & 16 & 5.0 & 70 & \multirow{5}{*}{0.141} \\
\hline $13-15$ & 23.0 & 64 & 21.5 & 56 & 24.0 & 60 & 22.5 & 48 & 25.9 & 49 & 24.5 & 51 & 23.5 & 328 & \\
\hline $16-18$ & 46.0 & 128 & 45.4 & 118 & 46.0 & 115 & 48.8 & 104 & 49.2 & 93 & 46.2 & 96 & 46.8 & 654 & \\
\hline $19-25$ & 24.5 & 68 & 24.2 & 63 & 24.8 & 62 & 23.0 & 49 & 19.0 & 36 & 19.7 & 41 & 22.8 & 319 & \\
\hline$>25$ & 1.1 & 3 & 3.1 & 8 & 2.0 & 5 & 1.9 & 4 & 1.6 & 3 & 1.9 & 4 & 1.9 & 27 & \\
\hline \multicolumn{16}{|c|}{ Number of sexual partners in lifetime } \\
\hline $1-10$ & 7.2 & 20 & 5.1 & 13 & 6.0 & 15 & 5.2 & 11 & 18.5 & 15 & 6.3 & 13 & 6.3 & 87 & \multirow{5}{*}{0.271} \\
\hline $11-100$ & 44.6 & 123 & 37.8 & 96 & 34.5 & 86 & 33.8 & 72 & 39.8 & 70 & 39.3 & 81 & 38.4 & 528 & \\
\hline $101-1,000$ & 41.7 & 115 & 47.2 & 120 & 48.2 & 120 & 48.4 & 103 & $44 \cdot 3$ & 78 & 42.7 & 88 & 45.4 & 624 & \\
\hline$>1,000$ & 6.5 & 18 & 9.8 & 25 & 11.2 & 28 & 12.7 & 27 & 7.4 & 13 & 11.7 & 24 & 9.8 & 135 & \\
\hline Unknown & NA & 2 & NA & 6 & NA & 1 & NA & 0 & NA & 13 & NA & 2 & NA & 24 & \\
\hline \multicolumn{16}{|c|}{ Number of sexual partners in the year before diagnosis } \\
\hline $0-5$ & $29 \cdot 3$ & 81 & 28.0 & 71 & 28.9 & 72 & 25.4 & 54 & 28.6 & 53 & 30.8 & 64 & 28.5 & 395 & \multirow{5}{*}{0.775} \\
\hline $6-25$ & 44.9 & 124 & 42.1 & 107 & 36.9 & 92 & 38.0 & 81 & 40.5 & 75 & 35.1 & 73 & 39.9 & 552 & \\
\hline $26-100$ & 12.0 & 33 & 13.4 & 34 & 17.3 & 43 & 28.6 & 61 & 19.5 & 36 & 22.1 & 46 & 18.3 & 253 & \\
\hline$>100$ & 13.8 & 38 & 16.5 & 42 & 16.9 & 42 & 8.0 & 17 & 11.4 & 21 & 12.0 & 25 & 13.4 & 185 & \\
\hline Unknown & NA & 2 & NA & 6 & NA & 1 & NA & 0 & NA & 4 & NA & 0 & NA & 13 & \\
\hline \multicolumn{16}{|l|}{ Sexual behaviour } \\
\hline Sex worker & 6.8 & 19 & 8.8 & 23 & 9.2 & 23 & 10.3 & 22 & 11.1 & 21 & 10.1 & 21 & 9.2 & 129 & 0.115 \\
\hline Use of drugs for sex & 86.0 & 239 & 84.2 & 219 & 87.2 & 218 & 83.1 & 177 & 78.8 & 149 & 78.8 & 164 & 83.4 & 1,166 & 0.008 \\
\hline $\begin{array}{l}\text { Condomless sex } \\
\text { under effect of drugs }\end{array}$ & $67 \cdot 3$ & 187 & 65.8 & 171 & 66.4 & 166 & 67.6 & 144 & 56.6 & 107 & 61.1 & 127 & 64.5 & 902 & 0.038 \\
\hline Chemsex sessions & \multicolumn{2}{|c|}{ Unk } & \multicolumn{2}{|c|}{ Unk } & 22.0 & 55 & 19.2 & 41 & 16.9 & 32 & 26.9 & 56 & 21.4 & 184 & 0.343 \\
\hline Apps for sex & \multicolumn{2}{|c|}{ Unk } & \multicolumn{2}{|c|}{ Unk } & 82.0 & 205 & 79.3 & 169 & 80.4 & 152 & 83.0 & 171 & 697 & 81.1 & 0.483 \\
\hline
\end{tabular}

NA: not applicable; Unk: unknown.

No data imputation has been made, all denominators for calculations were based on available information (excluding those with missing information).

clinical and behavioural markers considered to indicate high risk: history of STI (69.8\%), high number of sexual partners, condomless sexual practices under the effect of recreational substances (64.5\%) and the use of apps to search for sexual contacts $(77.4 \%)$. Several publications have associated the use of recreational drugs with an increased incidence of HIV and other STI [23]. Among the MSM analysed, $64.5 \%$ had condomless sexual relations under the influence of drugs, while among the rSCV, this percentage was higher (73.9\%) and similar to that found in a meta-analysis carried out among HIV-positive people and including 38 publications from 2000 to 2018 [24]. The USEX-Study, a study conducted in 22 hospitals in Madrid with 2,916 HIV-positive MSM, found that $29.1 \%$ used drugs for sex and, in our study, $28.9 \%$ of the rSCV participated in chemsex sessions [25]. It is fundamental to know the type of drug used and the route of administration. Substances such as mephedrone, methamphetamine, GHB, ketamine and poppers were strongly related to condomless sex and, as Pakianathan et al. noted, were identified as facilitating drugs for HIV transmission [26]. Even though their use by the parenteral route is uncommon, it is increasing, from $0.4 \%$ in 2014 to $4.3 \%$ in 2019. All PWID In our study used substances in a sexual context, data which are in line with Bui et al. who recorded that $4.7 \%$ of MSM monitored in an Australian Clinic practiced slam [27]. The growing popularity of chemsex coincides with a decrease in new HIV diagnoses, which could be explained by the high preventive efficacy of ART and PrEP. However, the use of preventive strategies such as PEP $(3.8 \%)$ or PrEP (1.1\%) was very rare in our study. The comparatively late funding in the implementation of PrEP in Spain could be one of the factors that explains the slow decline in new cases compared with other European or North American countries $[14,28]$. Funding of PrEP, combined with the other measures used in our country, may represent an opportunity to achieve a more substantial reduction in the number of new cases.

The use of apps to search for sexual contacts was high among MSM, especially among rSCV, and, as has been published elsewhere, the use of some social networks has been linked to risk behaviours for acquiring HIV and others STI [29]. In our work, $70.4 \%$ of HIV rSCV 


\section{FIGURE 3}

Frequency of condomless sexual practices under the effect of drugs, by substance type, recently seroconverted HIVpositive men who have sex with men, Madrid, 2014-2019 $(n=253)$

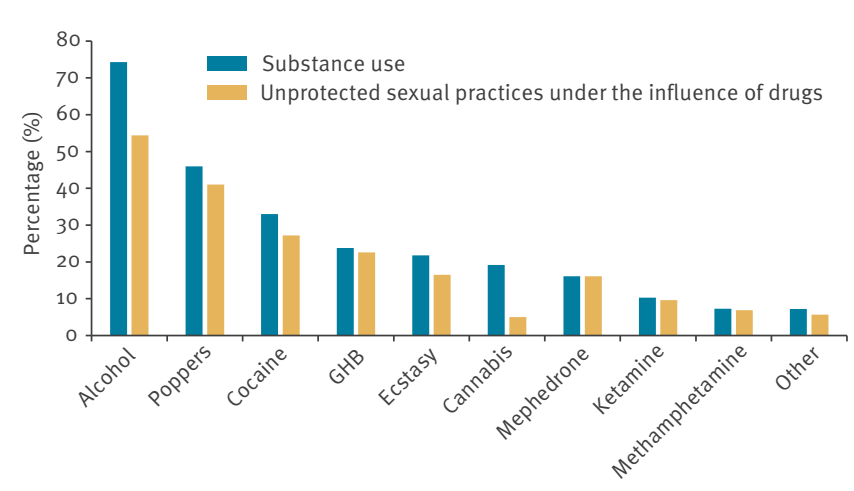

GHB: gamma hydroxybutyrate.

Substance use: Alcohol: $75.1 \%$ (190/253); poppers: $47.4 \%$ (120/253); cocaine: $33.2 \%(84 / 253)$; GHB: $24.5 \%(62 / 253)$; ecstasy $22.1 \%$ (56/253); cannabis: $19.4 \%$ (49/253); mephedrone 16.2 (41/253); ketamine $11.9 \%$ (30/253); methamphetamine: $7.1 \%$ $(18 / 253)$ and others: $6.3 \%(16 / 253)$. Unprotected sexual practices under the influence of drugs: Alcohol: $46.2 \%$ (117/253); poppers: $42.3 \%$ (107/253); cocaine: $27.3 \%$ (69/253); GHB: $23.3 \%$ (59/253); ecstasy $16.6 \%$ (42/253); cannabis: $4.7 \%$ (12/253); mephedrone 16.2 (41/253); ketamine $11.1 \%(28 / 253)$; methamphetamine: $6.7 \%(17 / 253)$ and others: $4.7 \%(12 / 253)$.

attributed the transmission of the virus to the use of these apps.

Our work could be limited by the fact that it was a monocentric study and analysed MSM, since most of the diagnoses in our centre were made among them. These data could not be extrapolated to heterosexual men and women or transgender women with very different sociodemographic, clinical and behavioural characteristics. It is an important line of research that should be studied. Despite this limitation, this is a study carried out at a reference STI/HIV clinic where care is offered without administrative barriers. Half of the people attended to are MSM, and many of them are of foreign origin, mainly Latin American. Because of the fact that it is the reference centre for PrEP in the Community of Madrid and because of its particular characteristics, it is considered a sentinel centre prepared to detect the epidemiological changes that accompany an HIV epidemic at an early stage. Knowing the profile of people newly infected with HIV allows for the design of preventive strategies specifically aimed at each individual or population group.

\section{Conclusion}

Our results reflect a reduction in new cases of HIV, in particular among MSM born in Spain, although the trend is not as significant as it is in other countries. Combination of HIV prevention strategies with the inclusion of PrEP and frequent HIV testing, should be reinforced among young MSM, especially those born in Latin America, those that use drugs for sex and those that use apps in search of sexual contacts.

\section{FIGURE 4}

Frequency of use of substances associated with condomless sex in recently seroconverted HIV-positive men who have sex with men, Madrid, 2014-2019 $(\mathrm{n}=253)$

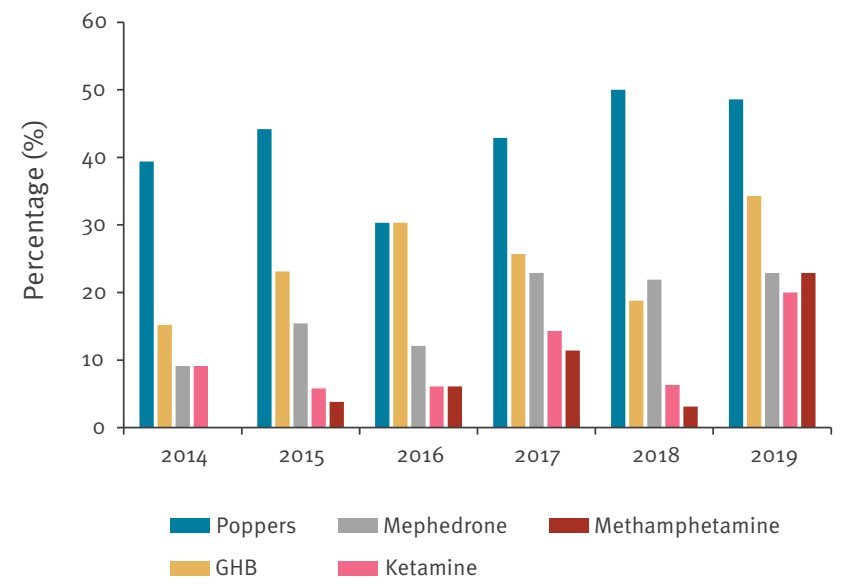

GHB: gamma hydroxybutyrate.

Totals are $n=66$ in 2014; $n=52$ in 2015; $n=33$ in 2016; $n=35$ in 2017; $\mathrm{n}=32$ in 2018; $\mathrm{n}=35$ in 2019.

Sandoval Study Group:

Estefania Hurtado, Monica García, Natividad Jerez, Sonsoles Del Corral, Marta Ruiz, Marta Gonzalvo, Elena Gutiérrez, Cristina Quirós, Víctor Rodríguez.

Acknowledgements

All the colleagues from the Centro Sanitario Sandoval, Hospital Clinico San Carlos, IdISSC.

Conflict of interest

None declared.

Authors' contributions

Oskar Ayerdi, Mar Vera, Teresa Puerta, Petunia Clavo, Juan Ballesteros, Clara Lejarraga, Manuel Enrique Fuentes, Montserrat Raposo, Vicente Estrada, Jorge Del Romero, and Carmen Rodríguez conceived and designed the study. All authors were responsible for patient inclusion, data collection, clinical follow up and help to write the manuscript. Manuel Enrique Fuentes and Oskar Ayerdi did the analysis and take the responsibility for the integrity of the data and the accuracy of the data analysis. All authors critically revised the manuscript and gave final approval for the final version. All members of the Sandoval Study Group were responsible for the patient inclusion, data collection and helped write the manuscript.

\section{References}

1. Centers for Disease Control (CDC). Pneumocystis pneumonia-Los Angeles. MMWR Morb Mortal Wkly Rep. 1981;30(21):250-2. PMID: 6265753

2. Marks G, Crepaz N, Janssen RS. Estimating sexual transmission of HIV from persons aware and unaware that they are infected with the virus in the USA. AIDS. 2006;20(10):1447-50. https:// 
doi.org/10.1097/01.aids.0000233579.79714.8d PMID: 16791020

3. Kolata G. FDA approves AZT. Science. 1987;235(4796):1570. https://doi.org/10.1126/science.235.4796.1570-b PMID: 3469754

4. Carpenter CC, Fischl MA, Hammer SM, Hirsch MS, Jacobsen DM, Katzenstein DA, et al. Antiretroviral therapy for HIV infection in 1996. Recommendations of an international panel. International AIDS Society-USA. JAMA. 1996;276(2):146-54. https://doi.org/10.1001/jama.1996.03540020068031 PMID: 8656507

5. INSIGHT START Study GroupLundgren JD, Babiker AG, Gordin F, Emery S, Grund B, et al. . Initiation of Antiretroviral Therapy in Early Asymptomatic HIV Infection. N Engl J Med. 2015;373(9):795-807. https://doi.org/10.1056/NEJMoa1506816 PMID: 26192873

6. Cohen MS, Chen YQ, McCauley M, Gamble T, Hosseinipour MC, Kumarasamy N, et al. Prevention of HIV-1 infection with early antiretroviral therapy. N Engl J Med. 2011;365(6):493-505. https://doi.org/10.1056/NEJMoa1105243 PMID: 21767103

7. Rodger AJ, Cambiano V, Bruun T, Vernazza P, Collins S, Degen 0 , et al. Risk of HIV transmission through condomless sex in serodifferent gay couples with the HIV-positive partner taking suppressive antiretroviral therapy (PARTNER): final results of a multicentre, prospective, observational study. Lancet. 2019;393(10189):2428-38. https://doi.org/10.1016/S01406736(19)30418-0 PMID: 31056293

8. Grant RM, Lama JR, Anderson PL, McMahan V, Liu AY, Vargas L, et al. Preexposure chemoprophylaxis for HIV prevention in men who have sex with men. N Engl J Med. 2010;363(27):2587-99. https://doi.org/10.1056/NEJMoa1011205 PMID: 21091279

9. European Medicines Agency (EMA). First medicine for HIV pre exposure prophylaxis recommended for approval in the EU. EMA/CHMP/496941/2016. London: EMA; 2016. Available from: https://www.ema.europa.eu/en/news/first-medicine-hiv-preexposure-prophylaxis-recommended-approval-eu

10. Center for Disease Control and Prevention (CDC). Preexposure prophylaxis for the prevention of HIV Infection in the United State - 2017 update. A clinical practice guideline. Atlanta: CDC; 2017. Available from: https://www.cdc.gov/hiv/pdf/risk/prep/ cdc-hiv-prep-guidelines-2017.pdf

11. World Health Organization (WHO). Policy brief: pre-exposure prophylaxis (口PrEP) $\mathrm{D}$ : WHO expands recommendation on oral pre- exposure prophylaxis of HIV infection (PrEP). Geneva: WHO; 2015. Available from: https://apps.who.int/iris/ handle/10665/197906

12. European AIDS Clinical Society (EACS). Guidelines. Version 9.0. Brussels: EACS; 2017. Available from: http://www.eacsociety. org/files/guidelines_9.0-english.pdf

13. Grupo de Estudio de Sida de la SEIMC (GeSIDA). Recomendaciones sobre Profilaxis Pre-Exposición en adultos para la Prevención de la Infección por VIH en España. [Recommendations on pre-exposure prophylaxis in adults for the prevention of HIV infection in Spain]. Madrid: GeSIDA; 2017. Spanish. Available from: https://gesida-seimc.org/ wp-content/uploads/2017/02/gesida-guiasclinicas-2016profilaxis_pre-exposicionVIH.pdf

14. de Sanidad M, Consumo y Bienestar S. Notas de Prensa. El Sistema Nacional de Salud (SNS) financia la PrEP desde mañana como medida de prevención del VIH en personas de alto riesgo. [Press release. The National Health System (SNS) finances PrEP starting tomorrow as an HIV prevention measure in people at high risk]. Madrid: Ministerio de Sanidad; 2019. Spanish. Available from: https://www.mscbs.gob.es/gabinete/ notasPrensa.do?id=4708

15. UNAIDS. Global HIV \& AIDS statistics - 2020 fact sheet. Geneva: UNAIDS. [Accessed: Dec 2020]. Available from: http:// unaids.mio.guru/en/resources/fact-sheet

16. Grulich AE, Guy R, Amin J, Jin F, Selvey C, Holden J, et al. Population-level effectiveness of rapid, targeted, highcoverage roll-out of HIV pre-exposure prophylaxis in men who have sex with men: the EPIC-NSW prospective cohort study. Lancet HIV. 2018;5(11):e629-37. https://doi.org/10.1016/S2352 3018(18)30215-7 PMID: 30343026

17. Epidemiology Section HIV. HIV epidemiology annual report 2019. San Francisco: San Francisco Department of Public Health; 2020. Available from: https://www.sfdph. org/dph/files/reports/RptsHIVAIDS/AnnualReport2019_ Indigo_20200929_Web_fixed.pdf

18. Brown AE, Mohammed H, Ogaz D, Kirwan PD, Yung M, Nash SG, et al. Fall in new HIV diagnoses among men who have sex with men (MSM) at selected London sexual health clinics since early 2015: testing or treatment or pre-exposure prophylaxis (PrEP)? Euro Surveill. 2017;22(25):30553. https://doi. org/10.2807/1560-7917.ES.2017.22.25.30553 PMID: 28662762
19. European Centre for Disease Prevention and Control (ECDC), World Health Organization Regional Office for Europe. (WHO/ Europe). HIV/AIDS surveillance in Europe 2019 - 2018 data. Stockholm: ECDC; Copenhagen: WHO/Europe; 2019. Available from: https://www.ecdc.europa.eu/en/publications-data/ hivaids-surveillance-europe-2019-2018-data

20. Unidad de Vigilancia de VIH. ITS y hepatitis. Vigilancia Epidemiológica del VIH y sida en España 2019: Sistema de Información sobre Nuevos Diagnósticos de VIH y Registro Nacional de Casos de Sida. Plan Nacional sobre el Sida. [Epidemiological surveillance of HIV and AIDS in Spain 2019: information system on new HIV diagnoses and national registry of AIDS cases. National Plan on AIDS]. Madrid:D.G. de Salud Pública / Centro Nacional de Epidemiología - ISCIII; 2020. Spanish. Available from: https://www.mscbs.gob.es/ ciudadanos/enfLesiones/enfTransmisibles/sida/vigilancia/ home.htm

21. Public Health England (PHE). Trends in HIV testing, new diagnoses and people receiving HIV-related care in the UK: data to the end of December 2019. Health Protection Report. 2020;14(20). Available from: http://allcatsrgrey.org.uk/wp/ wpfb-file/hpr2020_hiv19-pdf/

22. World Health Organization (WHO). Global health sector strategy on HIV 2016-2021. Towards ending AIDS. Geneva: WHO; 2016. Available from: https://www.who.int/ publications/i/item/WHO-HIV-2016.05

23. Hegazi A, Lee MJ, Whittaker W, Green S, Simms R, Cutts R, et al. Chemsex and the city: sexualised substance use in gay bisexual and other men who have sex with men attending sexual health clinics. Int J STD AIDS. 2017;28(4):362-6. https://doi.org/10.1177/0956462416651229 PMID: 27178067

24. Maxwell S, Shahmanesh M, Gafos M. Chemsex behaviours among men who have sex with men: A systematic review of the literature. Int J Drug Policy. 2019;63:74-89. https://doi. org/10.1016/j.drugpo.2018.11.014 PMID: 30513473

25. González-Baeza A, Dolengevich-Segal H, Pérez-Valero I, Cabello A, Téllez MJ, Sanz J, et al. Sexualized Drug Use (Chemsex) Is Associated with High-Risk Sexual Behaviors and Sexually Transmitted Infections in HIV-Positive Men Who Have Sex with Men: Data from the U-SEX GESIDA 9416 Study. AIDS Patient Care STDS. 2018;32(3):112-8. https://doi.org/10.1089/ apc.2017.0263 PMID: 29620925

26. Pakianathan M, Whittaker W, Lee MJ, Avery J, Green S, Nathan $B$, et al. Chemsex and new HIV diagnosis in gay, bisexual and other men who have sex with men attending sexual health clinics. HIV Med. 2018;19(7):485-90. https://doi.org/10.1111/ hiv.12629 PMID: 29790254

27. Bui H, Zablotska-Manos I, Hammoud M, Jin F, Lea T, Bourne A, et al. Prevalence and correlates of recent injecting drug use among gay and bisexual men in Australia: Results from the FLUX study. Int J Drug Policy. 2018;55:222-30. https://doi. org/10.1016/j.drugpo.2018.01.018 PMID: 29429864

28. Ayerdi Aguirrebengoa O, Vera García M, Portocarrero Nuñez A, Puerta López T, García Lotero M, Escalante Garcia C, et al. Implementing pre-exposure prophylaxis could prevent most new HIV infections in transsexual women and men who have sex with men. Rev Clin Esp (Barc). 2019;219(7):360-6. https:// doi.org/10.1016/j.rceng.2019.02.010 PMID: 30982539

29. Francisco Luz Nunes Queiroz AA, Lopes de Sousa ÁF, Evangelista de Araújo TM, Milanez de Oliveira FB, Batista Moura ME, Reis RK. A Review of Risk Behaviors for HIV Infection by Men Who Have Sex With Men Through Geosocial Networking Phone Apps. J Assoc Nurses AIDS Care. 2017;28(5):807-18. https://doi.org/10.1016/j.jana.2017.03.009 PMID: 28456472

\section{License, supplementary material and copyright}

This is an open-access article distributed under the terms of the Creative Commons Attribution (CC BY 4.0) Licence. You may share and adapt the material, but must give appropriate credit to the source, provide a link to the licence and indicate if changes were made.

Any supplementary material referenced in the article can be found in the online version.

This article is copyright of the authors or their affiliated institutions, 2021. 